\title{
Effect of preputial washing and antibiotic treatment on bacterial load and preservability of frozen bovine semen*
}

\author{
CHAMPAK BHAKAT ${ }^{1}$ and V S RAINA ${ }^{2}$ \\ National Dairy Research Institute, Karnal, Haryana 132001 India
}

Received: 12 September 2000; Accepted: 17 August 2001

\begin{abstract}
Preputial cavity is a main source of microbial contamination in semen. The semen samples were collected from 24 bovine bulls and extended with egg yolk citrate and treated with various combinations of antibiotics at different dose level. The different combinations were streptomycin + benzyl penicillin, streptomycin + benzyl penicillin + gentamicin, streptomycin + benzyl penicillin + ampicillin. Preputial washing was given by the antibiotic solution containing procaine penicillin. Without preputial washing, ejaculate from the same bull was taken as control. The effect of cryopreservation had a significant $(\mathrm{P}<0.01)$ influence on individual motility of spermatozoa, non-eosinophilic count, sperm abnormalities, acrosomal integrity and on total bacterial count. The treatment with different combinations of antibiotic on bacterial count was highly significant $(P<0.01)$. Preputial washing significantly $(P<0.01)$ reduced the total bacterial count. The effect of different combinations of antibiotic treatment on individual motility of spermatozoa, non-eosinophilic count, abnormal spermatozoa and acrosomal integrity of sperm cells was non-significant. The maximum reduction of bacterial count was observed by streptomycin + penicillin + gentamicin combination and followed by other combinations. The preputial washing coupled with streptomycin + penicillin + gentamicin fortification was the most efficient treatment for reducing bacterial load to a greater extent without affecting semen quality and preservability.
\end{abstract}

Key words: Antibiotic fortification, Bovine semen, Deep freezing, Preputial washing.

The present investigation was undertaken to study the effect of preputial washing coupled with antibiotics fortification on bacterial load and preservability of semen.

\section{MATERIALS AND METHODS}

Clinically healthy bovine bulls (24), (3- to 5- year-old,) belonging to artificial insemination section, National Dairy Research Institute, Karnal, were used as semen donor. The bulls were maintained under identical system of management. Semen was collected by artificial vagina (AV) technique taking all aseptic precautions. Preputial washing (PW) was given by the antibiotic solution containing procaine penicillin@ $1000 \mathrm{IU} / \mathrm{ml}$ of distilled water. Antibiotic solution $(50 \mathrm{ml})$ was introduced into preputial cavity by the help of catheter and preputial orifice was closed with a rubber band. After introducing solution, the preputial cavity region was massaged with hand. After 10 min interval, band was removed to allow the solution to come out from the cavity. The ejaculate from

*Part of the Master Degree Thesis (1994) submitted to NDRI, Deemed University, Karnal, Haryana, 132001.

Present address: 'Scientist NRCC, Bikaner Rajasthan 334001. ${ }^{2}$ Senior Scientist, Artificial Breeding Complex. the same bull without preputial washing, was taken as control. Each ejaculate was extended by using egg yolk citrate (EYC) extender which were treated with different combination of antibiotics, viz streptomycin and benzyl penicillin $(\mathrm{Na}$ salt) (SP) combination, streptomycin and benzyl penicillin and gentamicin sulphate (SPG) combination, streptomycin and benzyl penicillin and ampicillin (SPAmp) combination by split sample technique (Cruick Shank et al. 1995). For this purpose, each semen sample was split into 3 aliquots to mix EYC extender, which were treated with 3 different conbinations of antibiotics at following dose level viz: streptomycin@ $1000 \mathrm{~g} / \mathrm{ml}$ of extender, benzyl penicillin @1000 IU $/ \mathrm{ml}$ of extender, Gentamicin@1000 g/ml of extender, Ampirillin@1000 g/ml of extender. Streptomycin and benzyl penicillin combination was used as control group. The motility, eosinophilic spermatozoa (Bloom 1950, Hancock 1952), morphological abnormalities, acrosomal integrity (Hancock 1952) and standard plate count (SPC) were studied in the semen samples before and after freezing. The analysis was carried out by using standard statistical method (Snedecor and Cochran I981). For the analysis of SPC, the data were subjected to $\log$ transformation. The difference between treatment were analysed with the help of critical difference test. 


\section{RESULTS AND DISCUSSION}

The data on semen characteristics of antibiotic treatment alone and in combination with preputial washing, before and after deep freezing are given in Table 1.

A significant $(\mathrm{P}<0.01)$ drop in motility was observed because of the process of cryopreservation in antibiotic treatment group as well as in preputial washing + antibiotic treatment group. The live spermatozoa count registered a significant $(\mathrm{P}<0.01)$ decrease due to deep freezing in antibiotic treatment group and also in combination with preputial washing group. Freezing process, however, significantly $(\mathrm{P}<0.01)$ in- creased the abnormal cell counts in semen samples in both treatment groups. There was a significant $(\mathrm{P}<0.01)$ effect of cryopreservation on intact acrosome in antibiotic treatment case as well as preputial washing + antibiotic treatment. The effect of different combinations of antibiotic treatment on individual motility of spermatozoa, non-eosinophilic count, abnormal spermatozoa and acrosomal integrity of spermatozoa revealed that there was no significant difference between 3 different combinations of antibiotic treatment on semen characteristics in fresh as well as in post-thawed samples. Preputial washing + antibiotic treatment combination had a

Table 1. Mean value of semen characteristics before deep freezing (BDF) and after deep freezing (ADF)

\begin{tabular}{|c|c|c|c|c|c|c|}
\hline & \multicolumn{3}{|c|}{ Antibiotic treatment } & \multicolumn{3}{|c|}{ Preputial washing + Antibiotic treatment } \\
\hline & BDF & $\mathrm{ADF}$ & Overall average & $\mathrm{BDF}$ & $\mathrm{ADF}$ & Overall average \\
\hline \multicolumn{7}{|c|}{ Individual motility (\%) } \\
\hline \multirow[t]{2}{*}{ SP } & $67.78^{a}$ & $41.67^{\mathrm{b}}$ & $54.72^{\mathrm{c}}$ & $69.72^{\mathrm{d}}$ & $46.39^{\mathrm{e}}$ & $58.06^{r}$ \\
\hline & \pm 1.93 & \pm 1.84 & \pm 2.55 & \pm 1.64 & \pm 1.75 & \pm 2.28 \\
\hline \multirow{2}{*}{ SPG } & $67.78^{\mathrm{a}}$ & $43.06^{b}$ & $55.42^{c}$ & $70.00^{d}$ & $46.94^{e}$ & $58.47^{r}$ \\
\hline & \pm 1.68 & \pm 2.12 & \pm 2.46 & \pm 1.84 & \pm 1.72 & \pm 2.30 \\
\hline \multirow[t]{2}{*}{ SPAmp } & $69.07^{a}$ & $42.22^{b}$ & $55.69^{\mathfrak{c}}$ & $69.44^{d}$ & $46.67^{e}$ & $58.06^{r}$ \\
\hline & \pm 1.85 & \pm 2.05 & \pm 2.64 & \pm 1.80 & \pm 1.71 & \pm 2.27 \\
\hline Overall & $68.24^{\mathrm{a}}$ & $42.31^{b}$ & & $69.72^{d}$ & $46.67^{e}$ & \\
\hline Average & \pm 1.05 & \pm 1.34 & & \pm 1.21 & \pm 1.51 & \\
\hline \multicolumn{7}{|c|}{ Non-eosionophilic spermatozoa (\%) } \\
\hline \multirow[t]{2}{*}{$\mathrm{SP}$} & $74.61^{\mathrm{c}}$ & $54.89^{\mathrm{d}}$ & $64.75^{\circ}$ & $75.50^{r}$ & $54.28^{\mathrm{g}}$ & $64.89^{\mathrm{h}}$ \\
\hline & \pm 0.98 & \pm 1.40 & \pm 1.85 & \pm 0.99 & \pm 1.21 & \pm 1.93 \\
\hline \multirow[t]{2}{*}{ SPG } & $75.11^{\mathrm{c}}$ & $54.56^{d}$ & $64.83^{e}$ & $75.61^{\mathrm{r}}$ & $54.39^{\mathrm{g}}$ & $\quad 65.00^{\mathrm{h}}$ \\
\hline & \pm 0.91 & \pm 1.47 & \pm 1.92 & \pm 0.95 & \pm 1.23 & \pm 1.93 \\
\hline \multirow[t]{2}{*}{ SPAmp } & $74.33^{\mathrm{c}}$ & $54.56^{d}$ & $64.44^{\mathrm{e}}$ & $74.22^{\mathrm{f}}$ & $54.72^{\mathrm{g}}$ & $64.74^{\mathrm{h}}$ \\
\hline & \pm 1.28 & \pm 1.53 & \pm 1.93 & \pm 1.01 & \pm 1.14 & \pm 1.79 \\
\hline Overall & $74.69^{\mathrm{c}}$ & $54.67^{d}$ & & $75.11^{r}$ & $54.46^{\mathrm{g}}$ & \\
\hline Average & \pm 0.63 & \pm 0.85 & & \pm 0.64 & \pm 0.84 & \\
\hline \multicolumn{7}{|c|}{ Sperm abnormality (\%) } \\
\hline \multirow[t]{2}{*}{ SP } & $21.44^{a}$ & $26.67^{\mathrm{b}}$ & $24.06^{\mathrm{c}}$ & $19.39^{\mathrm{d}}$ & $24.22^{e}$ & $21.8^{r}$ \\
\hline & \pm 0.67 & \pm 0.99 & \pm 0.74 & \pm 0.62 & \pm 1.01 & \pm 0.72 \\
\hline \multirow[t]{2}{*}{ SPG } & $20.94^{a}$ & $27.33^{b}$ & $24.14^{\mathrm{c}}$ & $19.28^{\mathrm{d}}$ & $23.44^{\mathrm{e}}$ & $21.36^{r}$ \\
\hline & \pm 0.85 & \pm 1.01 & \pm 0.85 & \pm 0.76 & \pm 1.01 & \pm 0.72 \\
\hline \multirow[t]{2}{*}{ SPAmp } & $21.72^{\mathrm{a}}$ & $26.61^{b}$ & $29.17^{c}$ & $19.06^{d}$ & $24.67^{e}$ & $21.86^{r}$ \\
\hline & \pm 0.91 & \pm 0.82 & \pm 0.74 & \pm 0.75 & \pm 1.18 & \pm 0.84 \\
\hline Overall & $21.37^{\mathrm{a}}$ & $26.87^{b}$ & & $19.24^{d}$ & $24.11^{\mathrm{e}}$ & \\
\hline Average & \pm 0.48 & \pm 0.55 & & \pm 0.46 & \pm 0.45 & \\
\hline \multicolumn{7}{|c|}{ Acrosomal integrity (\%) } \\
\hline \multirow[t]{2}{*}{ SP } & $94.04^{\mathrm{c}}$ & $89.28^{\mathrm{d}}$ & $92.11^{\mathrm{e}}$ & $94.44^{r}$ & $89.22^{\mathrm{g}}$ & $91.53^{\mathrm{h}}$ \\
\hline & \pm 0.49 & \pm 0.53 & \pm 0.60 & \pm 0.70 & \pm 0.73 & \pm 0.67 \\
\hline \multirow[t]{2}{*}{ SPG } & $93.83^{\mathrm{c}}$ & $88.67^{d}$ & $91.25^{\mathrm{c}}$ & $94.83^{r}$ & $90.50^{\mathrm{g}}$ & $92.67^{\mathrm{h}}$ \\
\hline & \pm 0.39 & \pm 0.55 & \pm 0.55 & \pm 0.47 & \pm 0.81 & \pm 0.59 \\
\hline \multirow[t]{2}{*}{ SPAmp } & $93.83^{\mathrm{c}}$ & $87.67^{d}$ & $90.75^{\mathrm{e}}$ & $94.78^{r}$ & $88.78^{\mathrm{g}}$ & $91.78^{\mathrm{h}}$ \\
\hline & \pm 0.55 & \pm 0.75 & \pm 0.69 & \pm 0.43 & \pm 0.60 & \pm 0.62 \\
\hline Overall & $94.23^{\mathrm{c}}$ & $88.54^{d}$ & & $94.69^{r}$ & $89.50^{\mathrm{g}}$ & \\
\hline Average & \pm 0.29 & \pm 0.37 & & \pm 0.30 & \pm 0.39 & \\
\hline
\end{tabular}

Mean with similar superscripts do not differ significantly $(\mathrm{P}<0.01)$ from each other; (SP-streptomycin + benzyle penicillin, SPG streptomycin + benzyle penicillin + gentamicin, SPAmp - streptomycin + benzyle penicillin + ampicillin). 
Table 2. Mean value of total bacterial count ( $\mathrm{cfu} / \mathrm{ml}$ ) of semen samples before deep freezing (BDF) and after deep freezing (ADF)

\begin{tabular}{|c|c|c|c|c|c|c|}
\hline & \multicolumn{3}{|c|}{ Antibiotic treatment } & \multicolumn{3}{|c|}{ Preputial washing+antibiotic treatment } \\
\hline & BDF & $\mathrm{ADF}$ & Overall average & $\mathrm{BDF}$ & $\mathrm{ADF}$ & Overall average \\
\hline SP & $334.44^{\mathrm{a}}$ & $178.33^{b}$ & $256.39^{c}$ & $221.67^{\mathrm{d}}$ & $134.44^{e}$ & $178.06^{\mathrm{r}}$ \\
\hline SPG & $148.33^{8}$ & $87.22^{\mathrm{b}}$ & $117.78^{i}$ & $113.80^{\mathrm{i}}$ & $70.56^{\mathrm{k}}$ & $92.22^{1}$ \\
\hline SPAmp & $236.67^{\mathrm{m}}$ & $130.56^{n}$ & $183.61^{\circ}$ & $147.8^{\mathrm{p}}$ & $181.67^{\natural}$ & $124.72^{3}$ \\
\hline Overall average & $239.81^{\prime}$ & $132.04^{u}$ & & $161.04^{v}$ & $128.89^{w}$ & \\
\hline
\end{tabular}

Mean with similar superscripts do not differ significantly $(P<0.01)$ from each other. (SP, streptomycin+benzyle penicillin, SPGstreptomycin+benzyle penicillin+gentamicin, SPAmp-streptomycin+benzyle penicillin+ampicillin).

similar nonsignificant effect on individual motility of spermatozoa, non-eosinophilic count, sperm abnormalities and acrosomal integrity of spermatozoa before and after deep freezing. The non-significant effect of antibiotic on sperm motility as recorded during this investigation is consistent with the observations of Gangadhar et al. (1986). He also concluded that the combination of penicillin, streptomycin, chloramphenicol and either oxytetracycline or kanamycin did not affect the post-thaw motility of spermatozoa. They also reported that a combination of chloramphenicol $(250 \mu \mathrm{g} / \mathrm{ml})$, kanamycin $(250 \mu \mathrm{g} / \mathrm{ml})$ and oxytetracycline $(100 \mu \mathrm{g} / \mathrm{ml}) \mathrm{re}-$ duced the motility of sperm by $3 \%$ before freezing and by $15 \%$ after freezing. The present results revealed that the mo'tility was not affected by the combination of antibiotic used in the study. The combinations seem to be appropriate for semen fortification. Present study, emphasized that the combination of antibiotics used had no damaging effect on sperm survival during the freezing process. Live spermatozoa count was decreased after deep freezing. In general, the post-thaw motility obtained from this study was in conformity with the findings of Chinnaiya et al. (1979). In the present study, abnormalities rose with the freezing process. However, an almost identical increament was found for all treatments of antibiotic combination used in this investigation. From this, it was clear that morphology of spermatozoa was not affected by any of the antibiotic treatment combination. The harmless effect of different combinations of antibiotics on sperm morphology is consistent with the observation of Sykes and Mixner (1991). The acrosomal damage due to cryopreservation observed in the present study was in conformity with the report of Chinnaiya et al. (1979) and Nehring (1988). Terseron et al. (1977) found that spermatozoa were damaged at all the degree of dilution (1:10 and 1:20), cooling, freezing and thawing, thereby, resulting in cumulative acrosomal damage of about $40 \%$. It was clear from the results that the various combinations of antibiotics did not affect the acrosomes and thus revealing no interaction between various combination and freezing process. It further strengthens the previous findings that antibiotic combination have no adverse effect on preservability of bovine semen.

The data of mean value of total bacterial count (TBC) of semen samples before and after deep freezing is presented in
Table 2. Different combinations of antibiotic treatment were highly significant $(\mathrm{P}<0.01)$ on bacterial count in both groups viz: Antibiotic treatment fortification and when preputial washing coupled with antibiotic treatment in fresh and postthawed samples. The maximum reduction of TBC was observed by streptomycin + benzyl penicillin + gentamicin combination followed by streptomycin + benzyl penicillin + ampicillin and streptomycin + benzyl penicillin combinations. Preputial washing significantly $(\mathrm{P}<0.01)$ reduced the TBC in each antibiotic treated semen sub-samples in fresh and also in post-thawed states. Before deep freezing, maximum reduction of TBC was observed by PW + SPG treatment followed by PW + SPAmp and PW + SP as compared to samples without preputial washing. A similar trend of reduction of bacterial count was found after deep freezing when it compared with samples without preputial washing. The significant $(\mathrm{P}<0.01)$ reduction in bacterial counts as a result of preservation of semen samples at ultra low temperature $\left(-196^{\circ} \mathrm{C}\right)$ was also found. The reduction in bacterial count after deep freezing could be attributed to injury of some bacterial cells, sensitive to ultra low temperature $\left(-196^{\circ} \mathrm{C}\right)$ used for freezing purpose. The reduction in TBC in frozen semen samples after gentamicin treatment, recorded during this investigation was consistent with observation of Ahmed et al. (1989) who also found that gentamicin can control the bacterial growth in semen samples without affecting the semen quality after equilibration, after different interval of preservation and cryopreservation. Wayda (1991) suggested that gentamicin in combination with penicillin should be used for preparation of diluent for cryopreservation. Since preputial cavity commonly harbours some bacteria which may contaminate the senien and washing with antibiotic solution could reduce the contamination. Prasad and Pachauri (1985) reported that preputial washing with antibiotic solution could be able to reduce the bacterial contamination in ram semen by 61 to $77 \%$. The maximum reduction of bacterial count was observed by streptomycin + penicillin + gentamicin combination and followed by other combinations. The result of study suggests that preputial washing coupled with streptomycin + benzyl penicillin + gentamicin combination treatment is most efficient to reduce bacterial load to a greater extent in bovine semen, in fresh as well as in post thawed samples without 
affecting semen quality and preservability. It is followed by other combinations like preputial washing coupled with streptomycin + penicillin + ampicillin treatment combination.

\section{ACKNOWLEDGEMENTS}

The authors wish to express their sincere thanks to Dr OS Tomer, (Formerly Director, NDRI) and Dr V K Batish (Senior Scientist), Department of Microbiology, NDRI, Karnal, for providing necessary facilities for the present work.

\section{REFERENCES}

Ahmed K, Borgohain B N, Deca B C and Dutta G. 1989. Effect of streptopenicillin and gentamicin on bacterial load and quality of frozen semen. Indian Veterinary Journal 66(9): 886-92.

Bloom E.1950. A rapid staining method using eosin-nigrosin to distinguish between live and dead spermatozoa. Nordish Veterin Medizic 11(2): 58-61.

Chinnaiya G P, Sharma P A and Ganguli N C. 1979. The freezability of buffalo semen in different extenders. Indian Journal of Dairy Science 32(1): 93.

Cruick Shank R, Duguid J P, Marmoin B P and Swain R H A. 1975. Medical Microbiology: The Practice of Medical
Microbiology. 12th edn, Vol.2, Churchil, Livingstone, Edinbourgh.

Gangadhar K S, Rao A R and Subbaiah G. 1986. Effect of antibiotics on bacterial load in frozen semen of buffalo bulls. Indian Veterinary Journal 63(6): 489 -93.

Hancock J L. 1952. A method to observe the morphological abnormalities and acrosomal integrity of sperm cells. Journal of Experimental Biology 29: 445 .

Nehring H. 1988. Evaluation of acrosome integrity during semen storage. Animal Breeding Abstract 57(5): 3064.

Prasad J and Pachauri A K. 1985. Significance of intrapreputial wash in collecting low microbial count in ram semen. Livestock Advisor 10 (2): 9-11.

Snedecor W G and Cochran G W. 1981. Statistical Methods. Ox ford and IBH Publishing Co., Pvt. Ltd, New Delhi, India.

Sykes J G and Mixner J P. 1991. Toxicity to bull spermatozoa of various salt brands and lots of penicillin, streptomycin, aureomycin and chloromycin. Journal of Dairy Science 34: 34246.

Terseron F, Amir D and Schindler H. 1977. Acrosome damage of ram spermatozoa during dilution, cooling and freezing. Journal of Reproduction Fertility 51: 461-62.

Wayda E. 1991. Antibiotic resistance of bacterial strains isolated from bull semen. Medycyna Weterynaryjna 47(5): 214 -15. 